\title{
tert-Butyl Hydroquinone: an Effective Electrochemical Probe for Sensing Polymerase Chain Reaction and Loop-Mediated Isothermal Amplicons
}

\author{
Tsung-Tao Huang ${ }^{1,2}$, Veerappan Mani ${ }^{3}$, Chih-Hung Huang ${ }^{1}$, Jun Sheng Wang ${ }^{2}$, \\ Chung-Ming Chang ${ }^{4}$, Sheng-Tung Huang ${ }^{1,3}$ \\ ${ }^{1}$ Institute of Biochemical and Biomedical Engineering, National Taipei University of Technology, \\ Taipei, Taiwan, (R.O.C.) \\ ${ }^{2}$ Biomedical Instrument Technology Division, Instrument Technology Research Center, National \\ Applied Research Laboratories, Hsinchu, Taiwan, (R.O.C.) \\ ${ }^{3}$ Department of Chemical Engineering and Biotechnology, National Taipei University of Technology, \\ Taipei, Taiwan, (R.O.C.) \\ ${ }^{4}$ Department of Medical Biotechnology and Laboratory Science, Chang Gung University, Taoyuan \\ City, Taiwan (R.O.C.) \\ *E-mail: ws75624@ntut.edu.tw
}

doi: $10.20964 / 2017.04 .02$

Received: 4 January 2017 / Accepted: 31 January 2017 / Published: 12 March 2017

The quantitative monitoring of nucleic acid amplifications via polymerase chain reaction (PCR) and loop-mediated isothermal amplification (LAMP) are current approaches for high sensitive detection of DNA from pathogenic (micro) organisms. This work is continuous effort of our research group to find inexpensive and readily available DNA-redox intercalating probe for monitoring of amplicons. In this regard, we found tert-butyl hydroquinone (TBHQ), a readily available and low-cost redox molecule popularly used in food additive has good DNA binding ability and it is successful in the quantitative monitoring of DNA amplicons in PCR and LAMP. Our studies revealed that TBHQ has excellent DNA binding abilities and electrochemical behaviors in both PCR and LAMP buffer, and its binding parameters, binding constant, binding site size and diffusion coefficient are suitable for end point detection. The electrochemical end-point detections for monitoring DNA amplifications are established using target genomic DNA as models including $\lambda$ phage, calf thymus and $E$. coli and the method is verified and authenticated by traditional methods, such as fluorescence and turbidimetric methods. Besides, we found good recoveries in the determination of target tpc gene spiked in $\lambda$ phage, calf thymus and E. coli DNA.

Keywords: Polymerase chain reaction, LAMP, DNA, Biosensor, Molecular design, redox reporter

\section{FULL TEXT}


(C) 2017 The Authors. Published by ESG (www.electrochemsci.org). This article is an open access article distributed under the terms and conditions of the Creative Commons Attribution license (http://creativecommons.org/licenses/by/4.0/). 